\title{
The Chemokine Growth-Regulated Oncogene- $\alpha$ Promotes Spinal Cord Oligodendrocyte Precursor Proliferation
}

\author{
Shenandoah Robinson, ${ }^{1,2}$ Marie Tani, ${ }^{3}$ Robert M. Strieter, ${ }^{4}$ Richard M. Ransohoff, ${ }^{3}$ and Robert H. Miller ${ }^{2}$ \\ Departments of ${ }^{1}$ Neurosurgery and ${ }^{2}$ Neurosciences, School of Medicine, Case Western Reserve University, Cleveland, \\ Ohio 44106, 32Departments of Neurology and Neurosciences, Lerner Research Institute, Cleveland Clinic Foundation, \\ Cleveland, Ohio 44195, and ${ }^{4} T h e$ University of Michigan Medical Center, Department of Internal Medicine, \\ Ann Arbor, Michigan 48109
}

Chemokines, (chemotactic cytokines) are a family of regulatory molecules involved in modulating inflammatory responses. Here we demonstrate that the chemokine growth-regulated oncogene- $\alpha$ (GRO- $\alpha)$ is a potent promoter of oligodendrocyte precursor proliferation. The proliferative response of immature spinal cord oligodendrocyte precursors to their major mitogen, platelet derived growth factor (PDGF), is dramatically enhanced by GRO- $\alpha$ present in spinal cord conditioned medium. One source of GRO- $\alpha$ is a subset of spinal cord astrocytes. Cultures of astrocytes contain GRO- $\alpha$ mRNA and protein and secrete biologically active concentrations of $\mathrm{GRO}-\alpha$. In postnatal spinal cord white matter the location of GRO- $\alpha$-immunoreactive cells is developmentally regulated: GRO- $\alpha+$ cells first appear in ventral and later in dorsal spinal cord white matter. These results suggest that localized proliferation of oligodendrocytes is mediated by synergy between PDGF and GRO- $\alpha$.

Key words: oligodendrocytes; chemokines; GRO- $\alpha$; cell proliferation; development; spinal cord
The local control of oligodendrocyte precursor proliferation is critical to ensure that all axons in CNS white matter tracts are myelinated effectively. In the spinal cord, oligodendrocytes, the myelinating cells of the CNS, develop from precursors that arise in specific regions (Warf et al., 1991; Pringle and Richardson, 1993) and undergo extensive migration (Noll and Miller, 1993; Warrington et al., 1993) and proliferation (Gilmore, 1971; Miller et al., 1997) before differentiation. The mitogenic response of oligodendrocyte precursors depends on their level of maturity. Immature rodent oligodendrocyte precursors identified by labeling with monoclonal antibody (mAb) A2B5 (Raff et al., 1983) proliferate in response to platelet-derived growth factor (PDGFAA) (Noble et al., 1988; Richardson et al., 1988) and are the predominant cell population expressing the PDGF- $\alpha$ receptor in the developing CNS (Pringle et al., 1992; Pringle and Richardson, 1993). More mature precursors identified by the binding of mAb $\mathrm{O} 4$ proliferate primarily in response to basic fibroblast growth factor (bFGF) and not PDGF (Gard and Pfeiffer, 1990, 1993; Fok-Seang and Miller, 1994) suggesting that the sequential action of multiple factors regulate oligodendrocyte development.

In the spinal cord of postnatal animals, the majority of oligodendrocyte precursor proliferation occurs in presumptive white matter (Gilmore, 1971; Miller et al., 1997), where it is spatially and temporally regulated (Gilmore, 1971; Schwab and Schnell, 1989). In ventral regions most oligodendrocyte precursor proliferation is complete, and myelination begins in the first postnatal week. By contrast, in dorsal regions such as the cortical spinal

\footnotetext{
Received Aug. 3, 1998; revised Oct. 5, 1998; accepted Oct. 7, 1998.

This work was supported by National Institutes of Health Grants NS 36674 (to R.H.M.), 32151 (to R.M.R.), and RG2838 from the National Multiple Sclerosis Society. M.T. was supported by a Multiple Sclerosis fellowship. We thank Kim Dyer for outstanding assistance.

Correspondence should be addressed to Robert H. Miller, Department of Neurosciences, Case Western Reserve University School of Medicine, 10900 Euclid Avenue, Cleveland, OH 44106.

Copyright (C) 1998 Society for Neuroscience $\quad 0270-6474 / 98 / 1810457-07 \$ 05.00 / 0$
}

tract, maximal oligodendrocyte proliferation and myelination do not occur until the second or third postnatal week (Schwab and Schnell, 1989, 1991), implying an influence of the local environment on the generation of oligodendrocytes. Likewise, a transient rapid proliferation of very immature spinal cord oligodendrocyte precursors has recently been demonstrated (Calver et al., 1998). In addition, elevated local proliferation of oligodendrocyte precursors occurs in a number of pathological conditions in the adult CNS (Raine et al., 1981; Amat et al., 1991; Prineas et al., 1993), suggesting that environmental factors contribute to spatially localized oligodendrocyte precursor proliferation. The localization of oligodendrocyte proliferation is not simply a reflection of the distribution of the mitogen PDGF. Platelet-derived growth factor is synthesized by neurons (Yeh et al., 1991) and astrocytes (Pringle et al., 1989) and is ubiquitously distributed in the developing spinal cord (Calver et al., 1998).

Environmental signals influence oligodendrocyte precursor responses to PDGF (Robinson and Miller, 1996). For example, PDGF induces high levels of proliferation in A2B5+ cells in mixed spinal cord but not optic nerve cultures or purified cultures of A2B5+ cells (Robinson and Miller, 1996), suggesting that spinal cord contains an activity that enhances the response of oligodendrocyte precursors to PDGF. Oligodendrocyte precursor proliferative responses to PDGF can be influenced by bFGF, which promotes extended proliferation (Bogler et al., 1990; McKinnon et al., 1990), and the proteoglycan NG2 (Stallcup and Beasley, 1987), which enhances the PDGF-driven proliferative response (Nishiyama et al., 96). Neither of these two factors, nor ciliary neurotrophic factor or leukemia inhibitory factor, has properties consistent with the spinal cord activity (Robinson and Miller, 1996).

An alternate candidate for the spinal cord biological activity is a member of the chemokine family (Rollins, 1997). The chemokine growth-regulated oncogene- $\alpha$ (GRO- $\alpha$ ) was initially cloned as KC, a gene strongly induced in quiescent murine NIH 3 T3 fibroblasts by PDGF (Cochran et al., 1983). Human, rat, and hamster or- 


\section{A2B5+ Cell Proliferation}

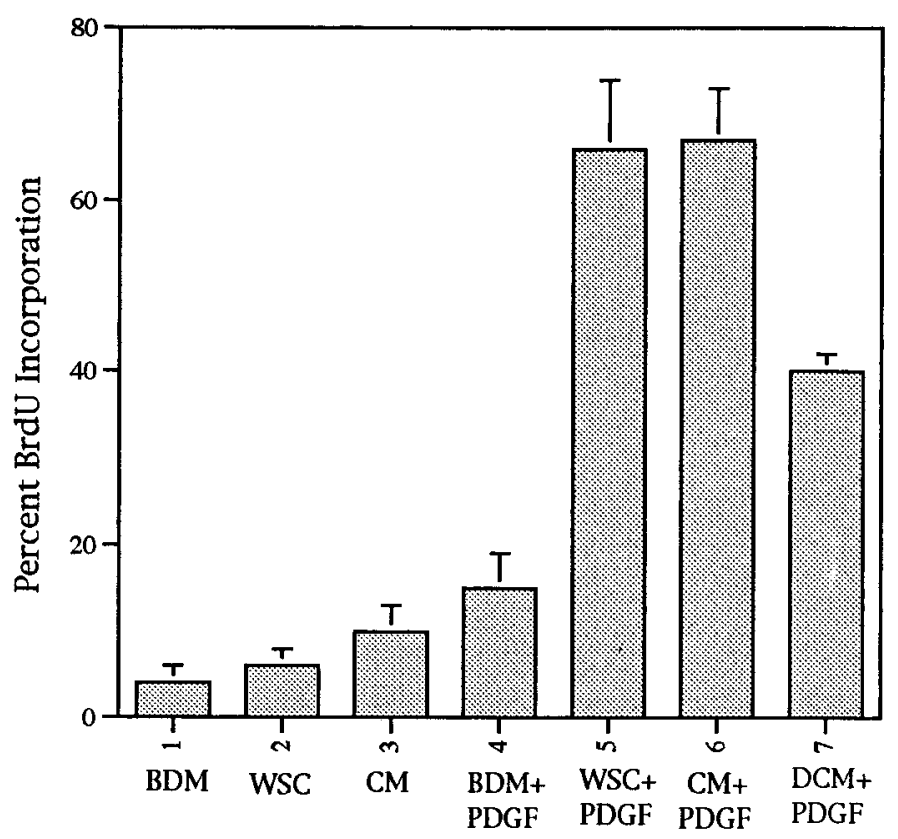

Growth Factors

Figure 1. Oligodendrocyte precursor proliferation is regulated by soluble factors in addition to PDGF. To determine the influence of CM on PDGFinduced proliferation of oligodendrocyte precursors, purified A2B5+ cells were grown in combinations of PDGF and CM. A2B5+ oligodendrocyte precursors have low levels of BrdU incorporation in basal defined medium $(B D M)$, in whole spinal cord cultures (WSC), and in the presence of spinal cord CM. PDGF-AA $(10 \mathrm{ng} / \mathrm{ml})$ alone had a limited effect on cell proliferation. By contrast, WSC or CM in combination with PDGF resulted in a 4.5-fold increase in cell proliferation. Denatured CM partially reduces the $\mathrm{BrdU}$ incorporation. The data represent the proportion of $\mathrm{A} 2 \mathrm{~B} 5+$ cells that incorporated BrdU. In all cases P0 rat spinal cord cells were cultured for $3 \mathrm{~d}$, with BrdU added during the last $18 \mathrm{hr}$. The data represent the mean $\pm \mathrm{SD}$ taken from two separate coverslips from three independent experiments.

thologs have since been identified, and their characterization has provided insights into the functions of GRO peptides. Anisowicz et al. (1987) isolated a gene that was overexpressed in human diploid fibroblasts, rendered tumorigenic by cDNAs from Chinese hamster ovary cells. Nontumorigenic sibling cell lines expressed lower levels of this gene, which was designated "gro." Independently, Richmond et al. (1988) described a peptide, designated melanocyte growth stimulatory activity (MGSA), secreted from human melanoma cells that possessed autocrine growth-promoting properties. The molecular identity of GRO- $\alpha$ and MGSA and a homologous relationship to KC were described early on (Oquendo et al., 1989), and a family of closely related human genes was characterized (Haskill et al., 1990). An avian homolog of GRO- $\alpha$, 9E3/CEF-4, was isolated from chick embryo fibroblasts during exponential growth and shown to be expressed in developing wings and in tissues undergoing neovascularization (Martins-Green and Bissell, 1990). These investigators proposed that CEF-4 might be involved in regulating angiogenesis; an extension of this hypothesis to mammalian CXC chemokines [interleukin 8 (IL-8) and GRO- $\alpha$ ] has gained substantial recent support (Strieter et al., 1995). Growth regulation by GRO peptides has now been described for cells of diverse lineages, including fibroblasts, melanocytes, and hemopoietic progenitors (Broxmeyer et al., 1993). In

\section{A2B5+ Cell Proliferation}

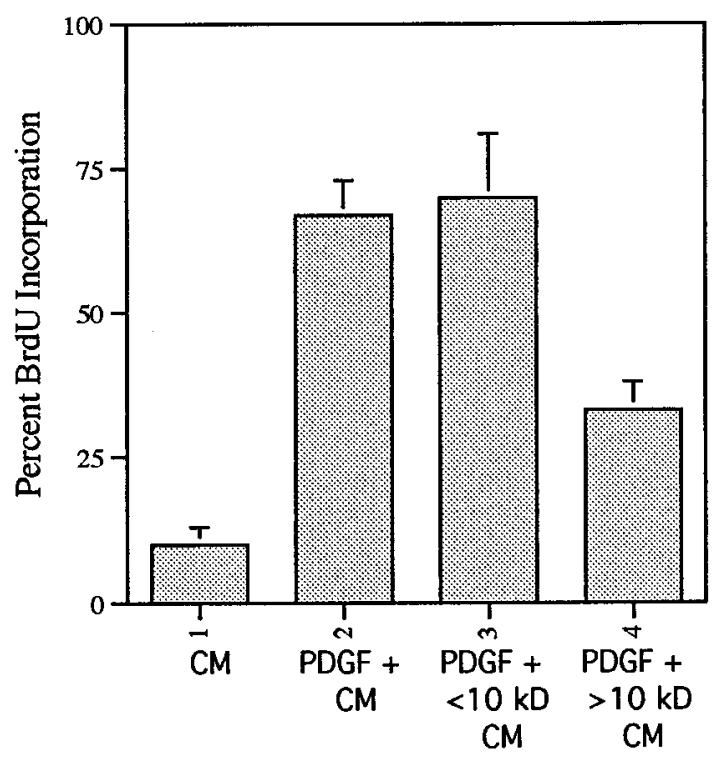

Growth Factors

Figure 2. The active factor in spinal cord CM was soluble with an $M_{\mathrm{r}}$ of $<10 \mathrm{kDa}$. CM was separated into fractions depending on size, and equivalent quantities were added to cultures of purified oligodendrocyte precursors. The fraction with an $\mathrm{Mr}<10 \mathrm{kDa}$ had a level of activity similar to that of whole $\mathrm{CM}$, whereas fractions $>10 \mathrm{kDa}$ had little proliferation-enhancing activity. Data represent the mean \pm SD for duplicate preparations in three independent experiments.

parallel, a substantial literature describing the roles of these molecules in inflammatory responses has appeared (Baggiolini et al., 1997; Rollins, 1997; Baggiolini, 1998).

Little is known about the role of CXC chemokines in the CNS. Elevated levels of CXC chemokine expression in the CNS are found in infection (Spanaus, 1997), tumors (Van Meir et al., 1992), ischemia (Liu, 1993), and demyelination (Glabinski et al., 1997). Overexpression of GRO- $\alpha$ in oligodendrocytes induced neutrophil invasion and astrogliosis (Tani, 1996). Similarly, leukocyte infiltration and blood-brain barrier breakdown occurred after overexpression of a CXC chemokine by astrocytes (Bell, 1996).

Here we demonstrate that GRO- $\alpha$ secreted by spinal cord astrocytes regulates oligodendrocyte precursor proliferation. In purified cultures of oligodendrocyte precursors, GRO- $\alpha$ markedly increased PDGF-induced proliferation in a narrow dose range. The presence of GRO- $\alpha+$ astrocytes in spinal cord white matter correlated spatially and temporally with elevated levels of oligodendrocyte precursor proliferation, suggesting that a combination of PDGF and GRO- $\alpha$ locally regulates oligodendrocyte precursor proliferation.

\section{MATERIALS AND METHODS}

Cell culture. Highly enriched populations of immature oligodendrocyte precursors were prepared by immunopanning with mAb A2B5 as previously described (Robinson and Miller, 1996). Cultures were grown in serum-free basal defined medium. To quantify cellular proliferation, a bromodeoxyuridine $(\mathrm{BrdU})$ incorporation assay was used and quantitated (Robinson and Miller, 1996). Briefly, cells were grown for the last $18 \mathrm{hr}$ in the presence of $10 \mu \mathrm{M} \mathrm{BrdU}$, and the number of BrdU-labeled cells was determined as described below. In experimental cultures, rat GRO- $\alpha /$ KC (Peprotech), PDGF-AA (Boehringer Mannheim, Indianapolis, IN), and $2 \mu \mathrm{g} / \mathrm{ml}$ goat anti-GRO- $\alpha$ (Santa Cruz Biotechnology, Santa Cruz, CA) were added as described. The anti-GRO- $\alpha$ antibody was specific for GRO- $\alpha$ and non-cross-reactive with GRO- $\beta$ and GRO- $\gamma$. 

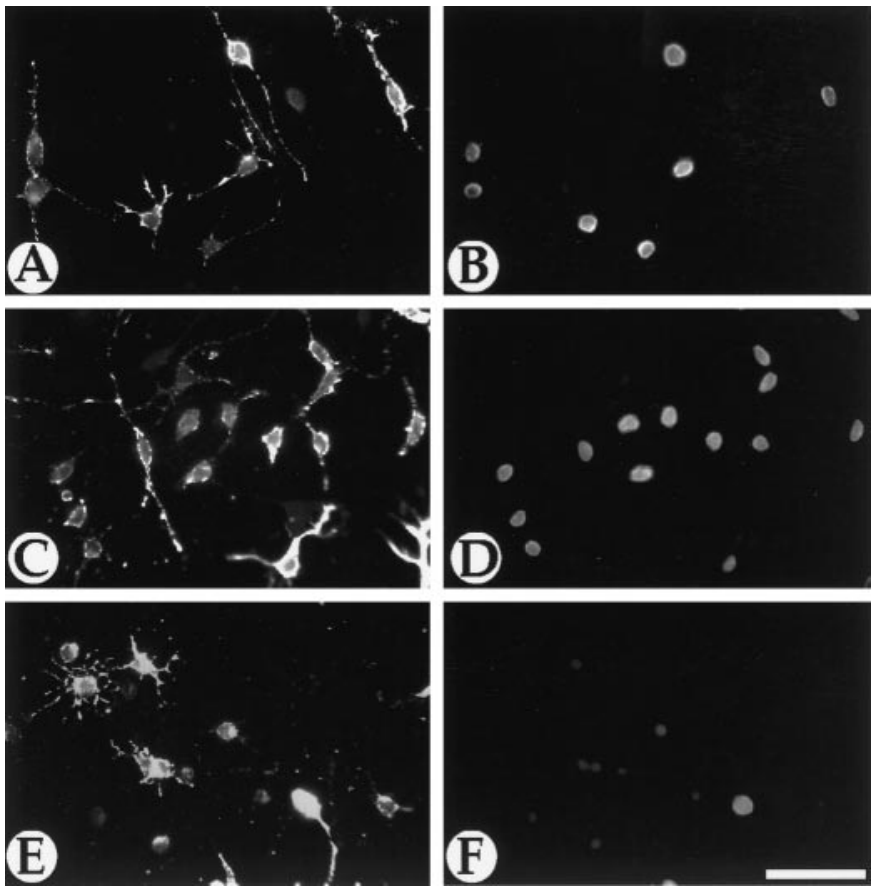

Figure 3. Neutralizing antibodies to GRO- $\alpha$ block the enhancement of oligodendrocyte precursor proliferation by spinal cord CM. A2B5 $(A, C, E)$ and $\operatorname{BrdU}(B, D, F)$ immunofluorescent staining of purified $\mathrm{A} 2 \mathrm{~B} 5+$ oligodendrocyte precursors cultured with PDGF and GRO- $\alpha(A, B)$, PDGF and spinal cord astrocyte $\mathrm{CM}(C, D)$, and PDGF, CM, and anti-GRO- $\alpha$ antibody $(E, F)$ is shown. The anti-GRO- $\alpha$ antibody neutralizes the marked increase in proliferation induced by $\mathrm{CM}$, suggesting that the neonatal spinal cord factor is closely homologous to GRO- $\alpha$. Scale bar, $20 \mu \mathrm{m}$.

Purified $\mathrm{O} 4+$ pro-oligodendroblasts were prepared using similar protocols with mAb O4 substituted for mAb A2B5. To determine the molecular mass of the biological activity, spinal cord conditioned medium (CM) was fractionated using Centriprep concentrators (Amicon, Beverly, MA) according to the manufacturer's directions. Fractions with maximal molecular weights of 10,30 , and $50 \mathrm{kDa}$ were prepared from postnatal day $0(\mathrm{P} 0)$ rat spinal cord cultures. The data represent the mean $\pm \mathrm{SD}$ of BrdU+/A2B5+ cells from at least six coverslips from three independent preparations.

Immunofluorescent labeling. Spinal cord cells were labeled with mAbs A2B5, O4, anti-GFAP, and anti-BrdU according to standard protocols (Robinson and Miller, 1996). For GRO- $\alpha$ labeling, mixed spinal cord cells were cultured in basal defined medium with $10 \mathrm{ng} / \mathrm{ml}$ PDGF, fixed with $1 \%$ formalin, incubated sequentially with $\mathrm{mAb}$ anti-GRO- $\alpha$ (Sigma, St. Louis, MO), biotin-conjugated anti-mouse IgG (ICN Pharmaceuticals, Costa Mesa, CA), and streptavidin Cy3 (Jackson ImmunoResearch, West Grove, PA). Cultures were then fixed with methanol-acetic acid and double-labeled with anti-GFAP antibodies (Robinson and Miller, 1996). Vibratome sections $(25 \mu \mathrm{m})$ of spinal cord previously fixed in Bouin's fixative were sequentially incubated with $0.3 \%$ hydrogen peroxide, $\mathrm{mAb}$ anti-GRO- $\alpha$, and biotin-conjugated anti-mouse $\mathrm{IgG}$, and labeling was visualized by DAB using a Vectastain kit (Vector Laboratories, Burlingame, CA). Sections were dehydrated through graded alcohol, cleared in Hemo-de (Fisher Scientific, Houston, TX), and mounted in Permount. In control cultures the primary antibody was deleted, and no specific labeling was seen. ELISAs for GRO- $\alpha$, GRO- $\beta$, and IL- 8 were performed as previously described (Keane, 1997) from coded samples of CM from two distinct cell cultures of both whole spinal cord and purified astrocytes. The purity of astrocyte cultures was determined by double labeling with mAbs A2B5, ED1 (Chemicon, Temecula, CA), and anti-GFAP to be $>85 \%$ type 1 astrocytes.

$R T-P C R$. Cells of the oligodendrocyte lineage were selectively removed from neonatal spinal cord cultures through complement-mediated cell lysis (Fok-Seang and Miller, 1994). The remaining cells ( $>85 \%$ GFAP + astrocytes) were collected. RNA was prepared by the acid-guanidinium method using TRIzol. GRO- $\alpha$ mRNA was analyzed by RT-PCR, using genespecific primers (forward, 5'-TCGCTTCTCTGTGCAGCGCT-3'; back-

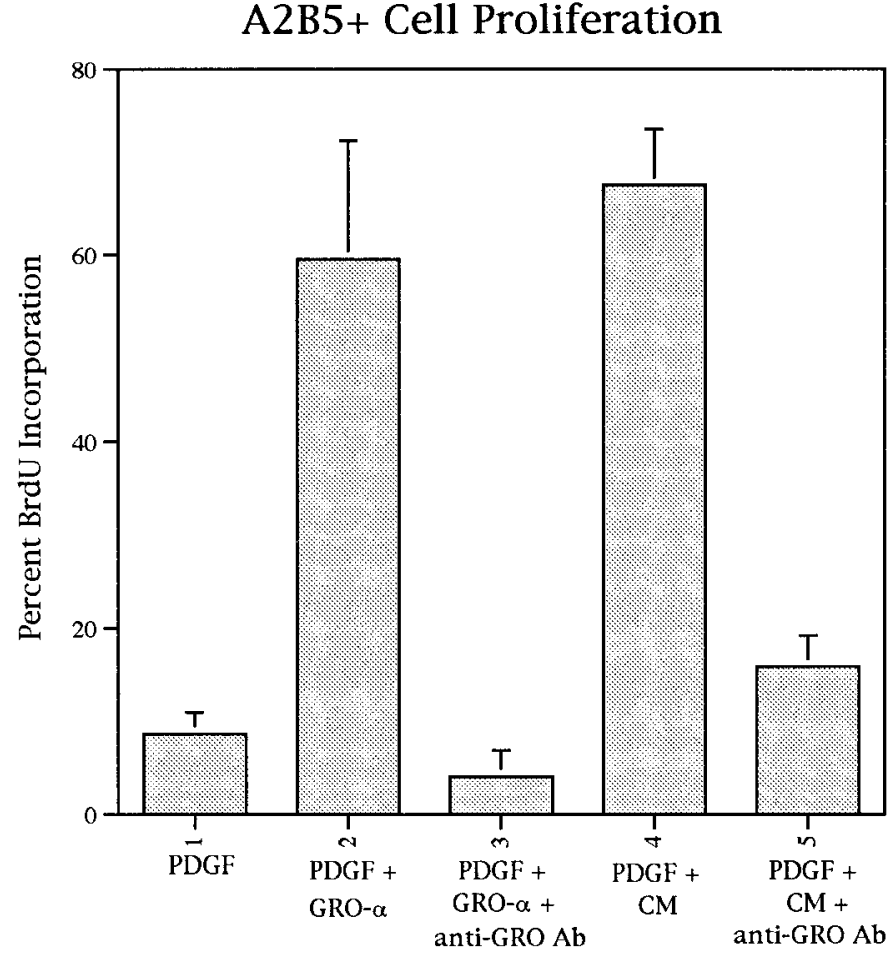

Growth Factors

Figure 4. Quantification of the effect of GRO- $\alpha$ on the proliferation of spinal cord oligodendrocyte precursors. Addition of GRO- $\alpha(0.5 \mathrm{ng} / \mathrm{ml})$ enhances PDGF (10 ng/ml)-driven proliferation of oligodendrocyte precursors to the same extent as spinal cord astrocyte $\mathrm{CM}$. The amplification of PDGF-driven proliferation by both GRO- $\alpha$ and $\mathrm{CM}$ is blocked by addition of anti-GRO- $\alpha$ antibody $(A b)$, suggesting that the active factor in $\mathrm{CM}$ is GRO- $\alpha$. Purified A2B5+ P0 rat spinal cord cells were cultured $2 \mathrm{~d}$ with BrdU added during the last $16 \mathrm{hr}$. The data represent the mean $\pm \mathrm{SD}$ of the proportion of cells that have incorporated BrdU taken from duplicate cultures in three independent experiments.

ward, 5'-GTGGTTGACACTTAGTGGTCTC-3') as previously described (Glabinski et al., 1997). PCR products were amplified for 20 cycles at $94^{\circ} \mathrm{C}$ for $2 \mathrm{~min}, 60^{\circ} \mathrm{C}$ for $2 \mathrm{~min}$, and $72^{\circ} \mathrm{C}$ for $1 \mathrm{~min}$. The PCR products were analyzed by Southern transfer and hybridization with a radiolabeled fulllength murine GRO- $\alpha$ probe. After high-stringency washes, a discrete band of expected size was detected by autoradiography in each of the two samples derived from two different cultures.

\section{RESULTS}

\section{Spinal cord CM enhances the proliferative response of oligodendrocyte precursors to PDGF}

To determine whether the enhanced proliferation of oligodendrocyte precursors to PDGF in spinal cord cultures reflected the influence of a soluble factor, the effect of spinal cord CM on PDGF-driven proliferation was assayed in purified cultures of $\mathrm{A} 2 \mathrm{~B} 5+$ cells. The proliferative response of purified immature oligodendrocyte precursors to PDGF is enhanced by spinal cord $\mathrm{CM}$ (Fig. 1). In control cultures in the absence of PDGF, $<5 \%$ of $\mathrm{A} 2 \mathrm{~B} 5+$ spinal cord cells proliferate. Likewise, in the presence of spinal cord CM or in whole spinal cord cultures, low levels of BrdU incorporation were seen. Addition of PDGF resulted in a small increase in purified $\mathrm{A} 2 \mathrm{~B} 5+$ cell proliferation in defined medium such that $\sim 16 \%$ of cells incorporated BrdU (Fig. 1). By contrast, when PDGF was added to whole spinal cord cultures containing all classes of neural cells, BrdU incorporation in the endogenous A2B5+ cells increased to $>65 \%$. Spinal cord CM in 
A2B5+ Cell Proliferation

Figure 5. The GRO- $\alpha$ enhancement of proliferation of oligodendrocyte precursors requires a threshold concentration of PDGF and is optimal at a concentration of $0.5 \mathrm{ng} / \mathrm{ml}$ GRO- $\alpha$. In the absence of PDGF, GRO- $\alpha$ is not mitogenic. At $5 \mathrm{ng} / \mathrm{ml}$ PDGF a limited enhancement of precursor proliferation is seen at concentrations of GRO- $\alpha>1 \mathrm{ng} / \mathrm{ml}$. By contrast, at $10 \mathrm{ng} / \mathrm{ml}$ an optimal 4.5 -fold increase in BrdU incorporation is seen at a concentration of $0.5 \mathrm{ng} / \mathrm{ml}$. This restricted optimal range of GRO- $\alpha$ concentrations is characteristic of chemokine responses. Purified P0 A2B5 + cells were cultured for $2 \mathrm{~d}$ with BrdU added during the last $16 \mathrm{hr}$.

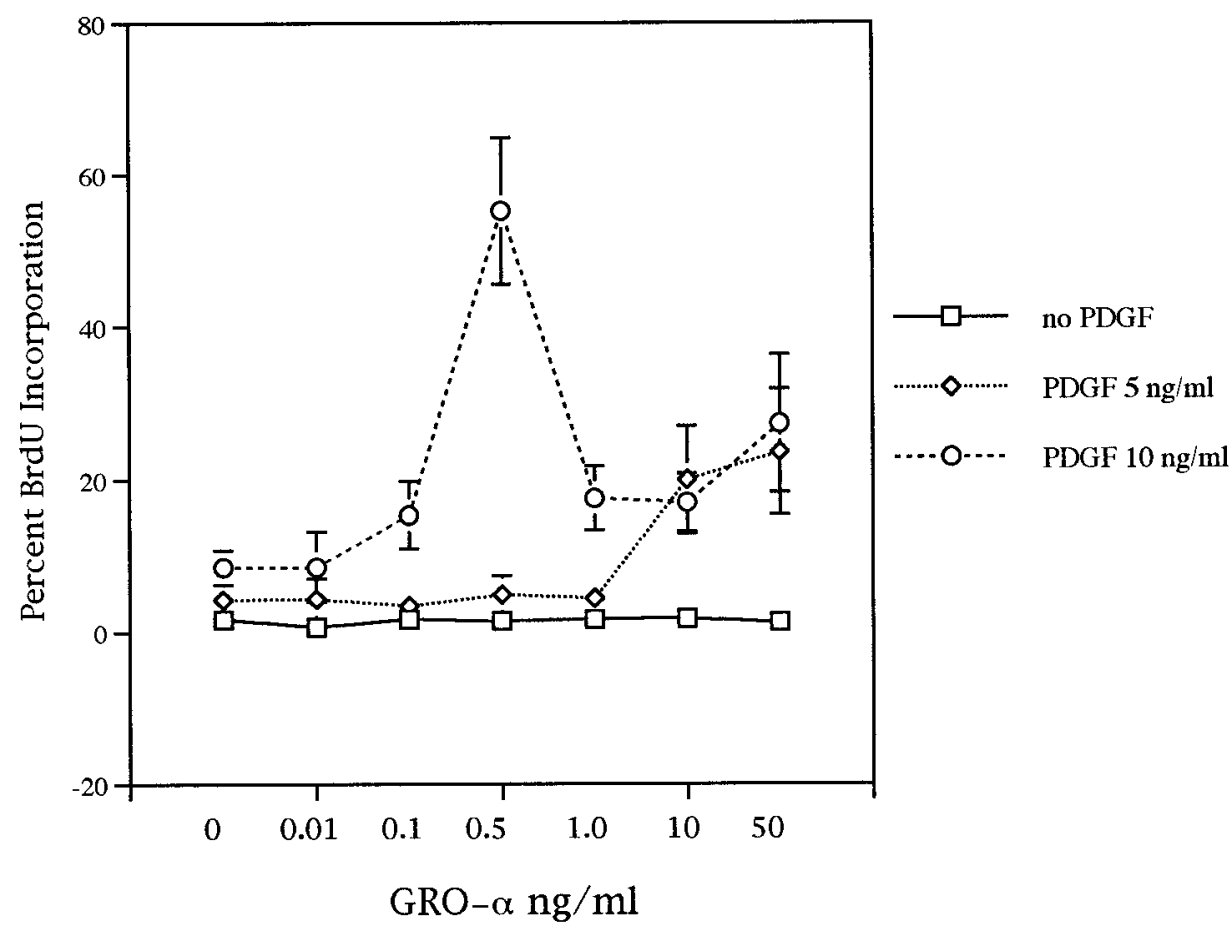

combination with PDGF increased proliferation 4.5-fold in purified cultures of A2B5+ spinal cord cells, and these levels were indistinguishable from those in whole spinal cord cultures (Fig. 1). These data suggest that spinal cord CM contains an activity, that while not an independent mitogen acts in synergy with PDGF to enhance the proliferation of oligodendrocyte precursors.

To test whether increasing levels of PDGF could replicate the effect of the spinal cord CM, concentrations of PDGF up to 30 $\mathrm{ng} / \mathrm{ml}$ in the absence of $\mathrm{CM}$ were added to purified cultures of $\mathrm{A} 2 \mathrm{~B} 5+$ cells, but no significant enhancement of proliferation was seen compared with $10 \mathrm{ng} / \mathrm{ml}$ PDGF (data not shown). Denaturing the $\mathrm{CM}$ reduced the synergistic effect significantly but did not totally abolish it (Fig. 1), suggesting the activity was a protein. To determine the molecular mass of the biological activity, spinal cord CM was size-fractionated, and the fractions were tested for synergy with PDGF. Addition of complete CM in the presence of PDGF resulted in $65 \%$ BrdU incorporation in purified A2B5+ oligodendrocyte precursors. Addition of the fractions with molecular weights $<10 \mathrm{kDa}$ resulted in similar levels $(67 \%)$ of BrdU incorporation as complete CM (Fig. 2). Addition of larger molecular weight fractions resulted in a slight increase in BrdU incorporation $(\sim 30 \%)$ over that seen with PDGF alone but was not comparable with that seen with the smaller fraction (Fig. 2), suggesting that although there may be multiple activities, the majority of the synergistic activity was present in the small-size fraction.

\section{Spinal cord CM activity can be replaced by the chemokine GRO- $\alpha$}

The relatively small apparent molecular weight associated with the biological activity suggested a member of the chemokine family. Because the chemokine GRO- $\alpha$ had established mitogenic activity (Anisowicz et al., 1987; Richmond et al., 1987; Richmond and Thomas, 1988), the effect of GRO- $\alpha$ on PDGF-driven oligodendrocyte precursor proliferation was assayed. In cultures of purified oligodendrocyte precursors, addition of $0.5 \mathrm{ng} / \mathrm{ml}$ GRO- $\alpha$ resulted in a fourfold increase in BrdU incorporation over that seen with PDGF alone (Figs. 3, 4). The level of precursor proliferation seen with a combination of GRO- $\alpha$ and PDGF (60\%) was similar to that seen with a combination of CM and PDGF (Figs. 3, 4). The synergistic effect between GRO- $\alpha$ and PDGF was totally abolished by addition of $2 \mu \mathrm{g} / \mathrm{ml}$ neutralizing anti-GRO antibodies (Fig. 4), and the neutralizing effects of the anti-GRO- $\alpha$ antibodies were reversed by addition of $100 \mathrm{ng} / \mathrm{ml}$ GRO- $\alpha$ (data not shown).

To determine whether the biological activity in $\mathrm{CM}$ was related to GRO- $\alpha$, neutralizing GRO- $\alpha$ antibody was added to $\mathrm{CM}$. Addition of anti-GRO- $\alpha$ essentially abolished the synergistic effect of spinal cord CM on PDGF-mediated proliferation of oligodendrocyte precursors (Figs. 3, 4), suggesting that the active factor in spinal cord CM is a GRO- $\alpha$ chemokine-like protein.

\section{The proliferative response to PDGF and GRO- $\alpha$ is concentration-dependent and a characteristic of A2B5+ precursor cells}

Like spinal cord CM, purified GRO- $\alpha$ was not an independent mitogen for oligodendrocyte precursors (Fig. 5). In the absence of PDGF no increase in BrdU incorporation was seen with GRO- $\alpha$ concentrations ranging from 0.01 to $50 \mathrm{ng} / \mathrm{ml}$. Thus, PDGF appears essential for A2B5+ cell proliferation. In the presence of 5 ng/ml PDGF, GRO- $\alpha$ had little effect on cell proliferation at concentrations $<1.0 \mathrm{ng} / \mathrm{ml}$. At higher concentrations (10-50 ng/ $\mathrm{ml})$ the proliferative response increased until $\sim 25 \%$ of cells incorporated BrdU (Fig. 5). In the presence of $10 \mathrm{ng} / \mathrm{ml}$ PDGF, a peak of proliferative response was seen with $0.5 \mathrm{ng} / \mathrm{ml}$ GRO- $\alpha$ (Fig. 5). This relatively narrow concentration dependence coupled with the threshold requirement for PDGF suggests that GRO- $\alpha$ enhancement of PDGF-driven oligodendrocyte precursor proliferation is precisely regulated in a dose-dependent manner.

The response of oligodendrocyte precursors to GRO- $\alpha$ is a characteristic of immature $(\mathrm{A} 2 \mathrm{~B} 5+)$ precursors not shared by more mature $\mathrm{O} 4+$ oligodendrocyte precursors. In parallel stud- 


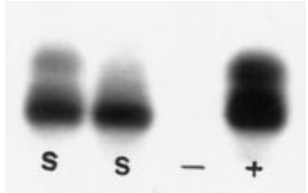

Figure 6. Neonatal rat spinal cord astrocytes contain GRO- $\alpha$ mRNA in vitro. Two independent cultures of purified spinal cord astrocytes were subjected to RT-PCR analysis with GRO- $\alpha$-specific probes. Both samples $(S)$ had a strong band of the appropriate size that comigrated with the major band detected in extracts of lipopolysaccharide-treated murine macrophages $(+)$. No band was detected in control $(-)$ samples from unstimulated macrophages.

ies, purified $\mathrm{O} 4+$ pro-oligodendrocytes were examined for responses to combinations of PDGF and GRO- $\alpha$. No increase in proliferation was seen with any combination of factor concentrations tested (data not shown), consistent with previous studies indicating that PDGF is not a major mitogen for these cells (Gard and Pfeiffer, 1990; Fok-Seang and Miller, 1994).

\section{Astrocytes contain GRO- $\alpha$ mRNA and protein and release biologically active quantities}

The major cell type in the spinal cord cultures used to generate $\mathrm{CM}$ was astrocytes. To independently confirm the identity of the $\mathrm{CM}$ biological activity as GRO- $\alpha$ and to demonstrate astrocytes as a cellular source, cultures enriched in spinal cord astrocytes $(>85 \%$ GFAP + cells) were assayed by RT-PCR using GRO- $\alpha-$ specific primers. Analysis of RT-PCR products by Southern blotting revealed that a single band at the expected size was detected (Fig. 6), indicating that cultured spinal cord type 1 astrocytes contained GRO- $\alpha$ mRNA. To determine whether all spinal cord astrocytes expressed GRO- $\alpha$ immunoreactivity, cultures were double-labeled with antibodies to GFAP and GRO- $\alpha$. Although $>85 \%$ of the cells were GFAP + , only a subpopulation $(\sim 25 \%)$ of the astrocytes cells were GRO- $\alpha$-immunoreactive (Fig. 7). There were no clearly distinctive morphological characteristics of the GRO- $\alpha+$ cells. The GRO- $\alpha$ immunoreactivity was localized in the cytoplasm and abundant in the perinuclear region and under high magnification appeared to be predominantly vesicular. Some non-GFAP + cells also expressed GRO- $\alpha$. Some of these cells were likely ED1 + microglia, which constituted $<1 \%$ of cells in the cultures, whereas others were immature astrocytes, residual neurons, or oligodendrocyte lineage cells.

To determine whether the chemokines produced by cultured astrocytes were released in detectable quantities into the culture medium, chemokine-specific ELISAs (Keane, 1997) were per-

$\begin{aligned} & \text { Table 1. Spinal cord and astrocyte conditioned media contain } \\
& \text { biologically active concentrations of GRO- } \boldsymbol{\alpha}\end{aligned}$
\begin{tabular}{llll} 
Culture & GRO- $\alpha(\mathrm{ng} / \mathrm{ml})$ & GRO- $\beta(\mathrm{ng} / \mathrm{ml})$ & $\mathrm{IL}-8(\mathrm{ng} / \mathrm{ml})$ \\
\hline Astrocytes & 0.463 & 0.022 & 0 \\
Astrocytes & 0.370 & 0 & 0 \\
Whole spinal cord & 0.424 & 0.026 & 0
\end{tabular}

The concentrations of three different chemokines in the conditioned media from whole spinal cord and purified astrocyte cultures was determined by specific ELISAs. Both spinal cord and astrocyte conditioned media contained $\sim 0.5 \mathrm{ng} / \mathrm{ml}$ GRO- $\alpha$ and low levels of GRO- $\beta$ but no detectable levels of the closely related human CXC-chemokine IL-8.

formed on CM derived from both complete spinal cord and purified astrocyte cultures. Both complete spinal cord and astrocyte CM contained biologically active levels of GRO- $\alpha$ (Table 1). The concentrations of GRO- $\alpha(0.5 \mathrm{ng} / \mathrm{ml})$ were similar to that which induced maximal increase in BrdU incorporation in the in vitro dose-response assay (Table 1, compare with Fig. 4). By contrast, conditioned media from both cultures contained only low levels of GRO- $\beta$, and the closely related chemokine IL- 8 was not detectable (Table 1). Taken together, these data provide strong evidence that the biological activity in CM that synergizes with PDGF to enhance the proliferation of oligodendrocyte precursors is the chemokine GRO- $\alpha$.

\section{The distribution of GRO- $\alpha+$ cells in the spinal cord is developmentally regulated}

In neonatal rat spinal cord the proliferation of oligodendrocyte precursors occurs primarily in the developing white matter (Miller et al., 1997). To determine whether GRO- $\alpha$ was expressed in the developing spinal cord in a pattern that correlated with oligodendrocyte precursor proliferation, transverse sections of spinal cord were labeled with an anti-GRO- $\alpha$ antibody. In cervical spinal cord of postnatal day 1 animals the majority of GRO- $\alpha+$ cells were seen in ventral and ventrolateral white matter. These GRO- $\alpha+$ cells had morphological characteristics of spinal cord white matter astrocytes (Liuzzi and Miller, 1987). The cells were mainly radially oriented and frequently had endfeet that terminated at the pial surface (Fig. 8). Fewer GRO- $\alpha$ cells were present in dorsal white matter; they were less intensely GRO- $\alpha$-immunoreactive and not obviously radially oriented. In gray matter, GRO- $\alpha+$ cells were present both ventrally and dorsally. Although some of these cells were most likely astrocytes, others were clearly neurons. In cervical spinal cord of postnatal day 8 animals the pattern of GRO- $\alpha$ expression was clearly
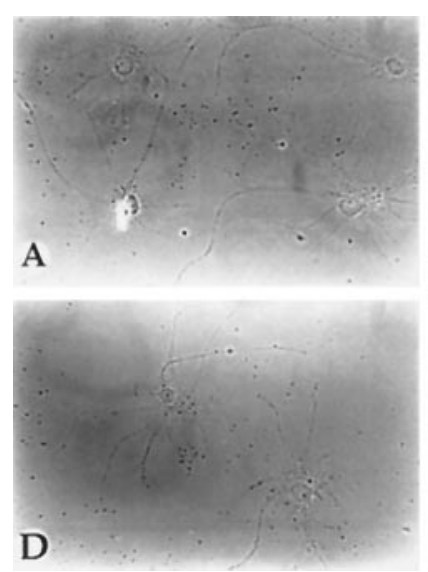
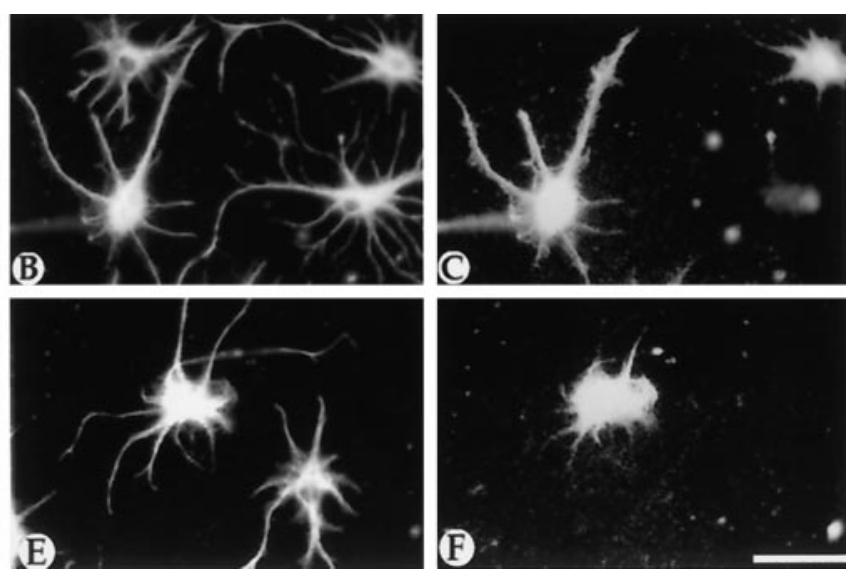

Figure 7. A subpopulation of astrocytes contains GRO- $\alpha$ protein. Cultures of spinal cord astrocytes were double-labeled with anti-GFAP $(B, E)$ and anti-GRO- $\alpha$ $(C, F)$ antibodies. Approximately $23 \%$ of the GFAP+ astrocytes in these cultures labeled with anti-GRO- $\alpha$ antibodies. $A, D$ Corresponding phase-contrast micrographs. Scale bar, $30 \mu \mathrm{m}$. 
Figure 8. The expression of GRO- $\alpha$ in spinal cord white matter astrocytes is developmentally regulated. In ventral spinal cord white matter $(A, C)$ radially oriented cells with feet on the pial surface express relatively high levels of GRO- $\alpha$ at P1 (A, arrows) but low levels at P8 $(C)$. By contrast, in dorsal spinal cord $(B, D)$ there are relatively low levels of GRO- $\alpha$ expression at $\mathrm{P} 1(B)$ and higher levels of expression in some cells at P8 (arrows). Scale bar, $30 \mu \mathrm{m}$.
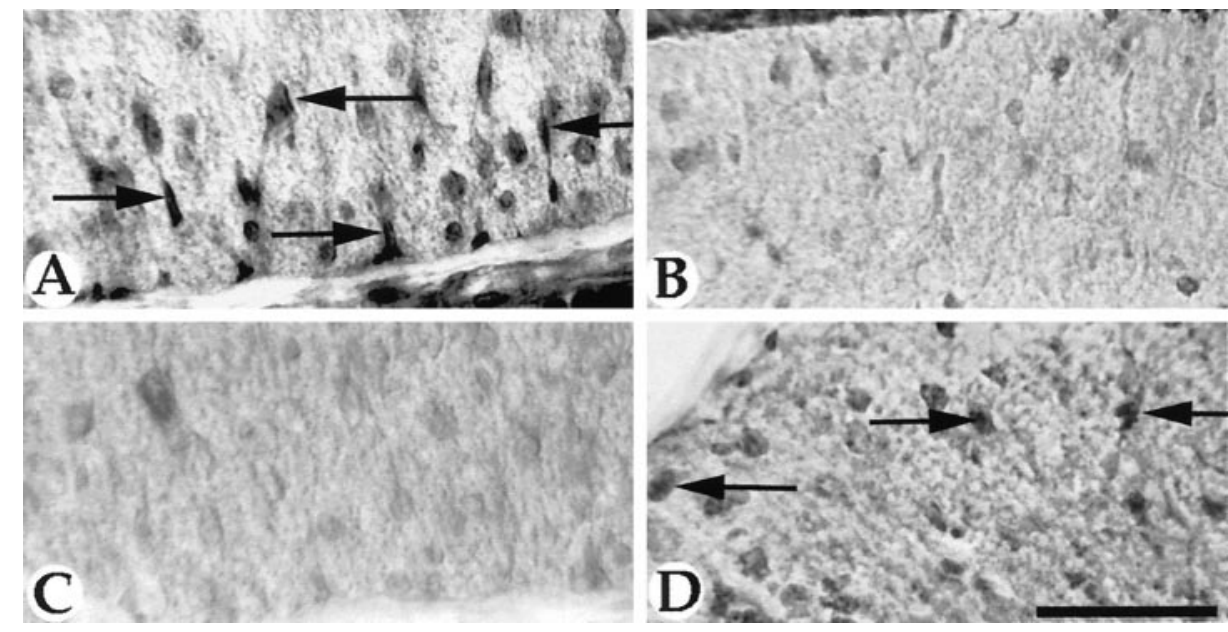

different. Far fewer GRO- $\alpha$ cells were present in gray matter and in ventral white matter compared with P1 animals; however, many more GRO- $\alpha+$ cells were detectable in dorsal spinal cord white matter (Fig. 8). This pattern of GRO- $\alpha$ expression in the developing spinal cord is consistent with the pattern of emergence of oligodendrocytes (Gilmore, 1971; Schwab and Schnell, 1989) and suggests that local control of proliferation of spinal cord oligodendrocyte precursors may be, in part, regulated by the local expression of GRO- $\alpha$.

\section{DISCUSSION}

Oligodendrocyte precursor proliferation is spatially and temporally regulated in the vertebrate CNS. How such local control of proliferation is mediated is currently unclear. Here we show that the chemokine GRO- $\alpha$ synergizes with PDGF to enhance rat oligodendrocyte precursor proliferation. GRO- $\alpha$ is produced by a subset of astrocytes and neurons in a developmentally regulated pattern. In vitro, cultured astrocytes secrete biologically active GRO- $\alpha$, whereas in vivo, the location of GRO- $\alpha+$ cells in spinal cord white matter is developmentally regulated. The proliferative response of oligodendrocyte precursors to GRO- $\alpha$ and PDGF is dependent on the concentration of both ligands and the maturational state of the cells. Below a threshold concentration of PDGF, GRO- $\alpha$ has no effect, whereas the maximal proliferative response occurs in a clearly defined GRO- $\alpha$ concentration range.

The interaction between GRO- $\alpha$ and PDGF suggests a novel mechanism for the precise local control of oligodendrocyte precursor proliferation. As an immediate response gene, GRO- $\alpha$ facilitates transient local bursts of oligodendrocyte precursor proliferation in the presence of threshold levels of PDGF. Thus, stimuli that induce the expression of GRO- $\alpha$ would promote the local proliferation of oligodendrocyte precursors. This hypothesis is consistent with the known requirements of PDGF for spinal cord oligodendrogenesis (Calver et al., 1998) and may explain the elevation of oligodendrocyte precursor proliferation seen during specific stages of early development (Calver et al., 1998).

The inducers of GRO- $\alpha$ expression in the CNS remain to be identified. In an astrocyte cell line, IL-1 $\beta$ and tumor necrosis factor- $\alpha$ (TNF- $\alpha)$ induce expression of the related CXC chemokine IL-8 (Anisowicz et al., 1991; Kasahara, 1991), and TNF- $\alpha$ is known to be expressed in the CNS under specific conditions (Liu, 1993). One well characterized inducer of GRO- $\alpha$ is PDGF (Cochran et al., 1983). Because both PDGF and GRO- $\alpha$ are required for maximal oligodendrocyte precursor proliferation, it is an attractive hypothesis that PDGF stimulates astrocyte production of GRO- $\alpha$. Focal elevations in PDGF as a result of astrocyte or neuronal stimulation would therefore provide both threshold levels of the mitogen and induction of GRO- $\alpha$, leading to a localized amplification of oligodendrocyte proliferation.

Expression of GRO- $\alpha$ may also regulate local elevated levels of oligodendrocyte precursor proliferation in the adult CNS. Enhanced oligodendrocyte precursor proliferation is seen adjacent to demyelinating lesions (Raine et al., 1988; Prineas et al., 1993). Although the expression of GRO- $\alpha$ adjacent to multiple sclerosis plaques has yet to be addressed, GRO- $\alpha$ is locally elevated in experimental autoimmune encephalitis, a model for multiple sclerosis (Glabinski et al., 1997). Several other pathological conditions result in elevated expression of GRO- $\alpha$, including ischemia (Liu, 1993), infection (Spanaus, 1997), and autoimmune demyelination (Glabinski et al., 1997), although the concomitant proliferation of oligodendrocyte precursors has not been assayed. Chemokines of the CXC family may play other roles in the nervous system in addition to enhancing oligodendrocyte precursor proliferation. Properties consistent with directing astrocyte migration (Heesen et al., 1996) and supporting the survival of distinct neuronal populations (Araujo and Cotman, 1993) have been described.

The finding that GRO- $\alpha$ enhances oligodendrocyte precursor proliferation suggests novel therapies in which GRO- $\alpha$ functions are enhanced to boost oligodendroglial progenitor proliferation and to improve neurological recovery after demyelination. Alternatively, dysregulated chemokine expression might contribute to abnormal glial proliferation that occurs in gliosis and tumors. In conclusion, the regulation of oligodendrocyte precursor proliferation by synergy between GRO- $\alpha$ and PDGF provides a novel mechanism for the precise regulation of glial proliferation in the developing vertebrate CNS.

\section{REFERENCES}

Amat JA, Fields KL, Schubart UK (1991) Distribution of phosphoprotein p19 in rat brain during ontogeny-stage-specific expression in neurons and glia. Dev Brain Res 60:205-218.

Anisowicz A, Bardwell L, Sager R (1987) Constitutive overexpression of a growth-related gene in transformed Chinese hamster and human cells. Proc Natl Acad Sci USA 84:7188-7192.

Anisowicz A, Messineo M, Lee SW, Sager R (1991) An NF-kappa B-like transcription factor mediates IL-1/TNF-alpha induction of gro in human fibroblasts. J Immunol 147:520-527.

Araujo DM, Cotman CW (1993) Trophic effects of interleukin-4 and -7 and -8 on hippocampal neuronal cultures: potential involvement of glial derived factors. Brain Res 600:49-55. 
Baggiolini M (1998) Chemokines and leukocyte traffic. Nature 392:565-568

Baggiolini M, Dewald B, Moser B (1997) Human chemokines: an update. Annu Rev Immunol 15:675-705.

Bell MD (1996) Recombinant human adenovirus with rat MIP-2 gene insertion causes prolonged PMN recruitment to the murine brain. Eur J Neurosci 8:1803-1811.

Bogler O, Wren D, Barnett SC, Land H, Noble M (1990) Cooperation between two growth factors promotes extended self-renewal and inhibits differentiation of oligodendrocyte-type-2 astrocyte (O-2A) progenitor cells. Proc Natl Acad Sci USA 87:6368-6372.

Broxmeyer HE, Sherry B, Cooper S, Lu L, Maze R, Beckmann MP, Cerami A, Ralph P (1993) Comparative analysis of the human macrophage inflammatory protein family of cytokines (chemokines) on proliferation of human myeloid progenitor cells. Interacting effects involving suppression, synergistic suppression and blocking of suppression. J Immunol 150:3448-3458.

Calver AR, Hall AC, Yu W-P, Walsh FS, Heath JK, Betsholtz C, Richardson WD (1998) Oligodendrocyte population dynamics and the role of PDGF in vivo. Neuron 20:869-882.

Cochran BJ, Reffel AC, Stiles CD (1983) Molecular cloning of gene sequences regulated by platelet derived growth factor. Cell 33:939-947.

Fok-Seang J, Miller RH (1994) Distribution and differentiation of A2B5+ glial precursors in the developing rat spinal cord. J Neurosci Res 37:219-235.

Gard AL, Pfeiffer SE (1990) Two proliferative stages of the oligodendrocyte lineage (A2B5+O4- and $\mathrm{O} 4+\mathrm{GalC}-$ ) under different mitogenic control. Neuron 5:615-625.

Gard AL, Pfeiffer SE (1993) Glial cell mitogens bFGF and PDGF differentially regulate development of $\mathrm{O} 4+\mathrm{GalC}$-oligodendrocyte progenitors. Dev Biol 159:618-630.

Gilmore SA (1971) Neuroglial populations in the spinal white matter of neonatal and early postnatal rats: an autoradiographic study of numbers of neuroglia and changes in their proliferative activity. Anat Rec 171:283-292.

Glabinski A, Tani M, Streiter R, Tuohy V, Ransohoff R (1997) Synchronous synthesis of $\mathrm{a}$ and $\mathrm{b}$ chemokines by cells of diverse lineage in the central nervous system of mice with relapses of experimental autoimmune encephalomyelitis. Am J Pathol 150:617-630.

Haskill S, Peace A, Morris J, Sporn SA, Anisowicz A, Lee SW, Smith T, Martin G, Ralph P, Sager R (1990) Identification of three related human GRO genes encoding cytokine functions. Proc Natl Acad Sci USA 87:7732-7736.

Heesen M, Tanabe S, Berman MA, Yoshizawa I, Luo Y, Kim RJ, Post TW, Gerard C, Dorf ME (1996) Mouse astrocytes respond to the chemokines MCP-1 and KC but reverse transcriptase-polymerase chain reaction does not detect mRNA for the $\mathrm{KC}$ or new MCP-1 receptor. J Neurosci Res 45:382-391.

Kasahara T (1991) IL-1 and TNF-alpha induction of IL-8 and monocyte chemotactic and activating factor (MCAF) mRNA expression in a human astrocytoma cell line. Immunology 74:60-67.

Keane MP (1997) The CXC chemokines. IL8 and IP10 regulate angiogenic activity in idiopathic pulmonary fibrosis. J Immunol 159:1437-1443.

Liu T (1993) Cytokine-induced neutrophil chemoattractant mRNA expressed in cerebral ischemia. Neurosci Lett 164:125-128.

Liuzzi FJ, Miller RH (1987) Radial oriented astrocytes in the normal adult rat spinal cord. Brain Res 403:385-388.

Martins-Green M, Bissell MJ (1990) Localization of 9E3/CEF-4 in avian tissues: expression is absent in Rous sarcoma virus induced tumors but is stimulated by injury. J Cell Biol 110:581-595.

McKinnon RD, Matsui T, Dubois-Dalcq M, Aaronson SA (1990) FGF modulates the PDGF-driven pathway of oligodendrocyte development. Neuron 5:603-614.

Miller RH, Payne J, Milner L, Zhang H, Orentas D (1997) Spinal cord oligodendrocytes develop from a limited number of migratory, highly proliferative precursors. J Neurosci Res 50:157-168.

Noble M, Murray K, Stroobant P, Waterfield MD, Riddle P (1988) Platelet-derived growth factor promotes division and motility and inhibits premature differentiation of the oligodendrocyte/type-2 astrocyte progenitor cell. Nature 333:560-562.

Noll E, Miller RH (1993) Oligodendrocyte precursors originate at the ventral ventricular zone dorsal to the ventral midline in the embryonic rat spinal cord. Development 118:563-573.
Oquendo P, Alberta J, Wen D, Graycar JL, Derynck R, Stiles CD (1989) The platelet-derived growth factor-inducible $\mathrm{KC}$ gene encodes a secretory protein related to platelet-granule proteins. J Biol Chem 264:4133-4137.

Prineas JW, Barnard RO, Kwon EE, Sharer LR, Cho ES (1993) Multiple sclerosis: remyelination of nascent lesions. Ann Neurol 33:137-151.

Pringle NP, Richardson WD (1993) A singularity of PDGF alpha-receptor expression in the dorsoventral axis of the neural tube may define the origin of the oligodendrocyte lineage. Development 117:525-33.

Pringle N, Collarini EJ, Mosley MJ, Heldin CH, Westermark B, Richardson WD (1989) PDGF A chain homodimers drive proliferation of bipotential (O-2A) glial progenitor cells in the developing rat optic nerve. EMBO J 8:1049-1056.

Pringle NP, Mudhar HS, Collarini EJ, Richardson WD (1992) PDGF receptors in the rat CNS: during late neurogenesis, PDGF alphareceptor expression appears to be restricted to glial cells of the oligodendrocyte lineage. Development 115:535-551.

Raff MC, Miller RH, Noble M (1983) A glial progenitor cell that develops in vitro into an astrocyte or an oligodendrocyte depending on culture medium. Nature 303:390-396.

Raine CS, Scheinberg L, Waltz JM (1981) Multiple sclerosis: oligodendrocyte survival and proliferation in an active established lesions. Lab Invest 45:534-534.

Raine CS, Moore GRW, Hintzen R, Traugott U (1988) Induction of oligodendrocyte proliferation and remyelination after chronic demyelination. Relevance to multiple sclerosis. Lab Invest 59:467-479.

Richardson WD, Pringle N, Mosley MJ, Westermark B, Dubois-Dalcq M (1988) A role for platelet-derived growth factor in normal gliogenesis in the central nervous system. Cell 53:309-319.

Richmond A, Thomas HG (1988) Melanoma growth stimulatory activity: isolation from human melanoma tumors and characterization of tissue distribution. J Cell Biochem 36:185-198.

Richmond A, Thomas HG, Roy RG (1987) Separation of melanoma growth stimulatory activity and human type-alpha transforming growth factor. Methods Enzymol 146:112-126.

Richmond A, Balentien E, Thomas HG, Flaggs G, Barton DE, Spiess J, Bordoni R, Francke U, Derynck R (1988) Molecular characterization and chromosomal mapping of melanoma growth stimulatory activity, a growth factor structurally related to beta-thromboglobulin. EMBO J 7:2025-2033.

Robinson S, Miller RH (1996) Environmental enhancement of growth factor mediated oligodendrocyte precursor proliferation. Mol Cell Neurosci 8:38-52.

Rollins B (1997) Chemokines. Blood 90:909-928.

Schwab ME, Schnell L (1989) Region-specific appearance of myelin constituents in the developing rat spinal cord. J Neurocytol 18:161-169.

Schwab ME, Schnell L (1991) Channeling of developing rat corticospinal tract axons by myelin-associated neurite growth inhibitors. J Neurosci 11:709-721.

Spanaus KS (1997) C-X-C and C-C chemokines are expressed in the cerebrospinal fluid in bacterial meningitis and mediate chemotactic activity on peripheral blood-derived polymorphonuclear and mononuclear cells in vitro. J Immunol 158:1956-1964.

Stallcup WB, Beasley L (1987) Bipotential glial precursor cells of the optic nerve express the NG2 proteoglycan. J Neurosci 7:2737-2744.

Strieter RM, Polverini PJ, Arenberg DA, Kunkel SL (1995) The role of CXC chemokines as regulators of angiogenesis. Shock 4:155-160.

Tani M (1996) Neutrophil infiltration, glial reaction and neurological disease in transgenic mice expressing the chemokine $\mathrm{N} 51 / \mathrm{KC}$ in oligodendrocytes. J Clin Invest 98:529-539.

Van Meir E, Ceska M, Effenberger F, Walz A, Grouzmann I, Desbaillets I, Frei K, Fontana A, de Tribolet N (1992) Interleukin-8 is produced by neoplastic and infectious diseases of the human central nervous system. Cancer Res 52:4297-4305.

Warf BC, Fok Seang J, Miller RH (1991) Evidence for the ventral origin of oligodendrocyte precursors in the rat spinal cord. J Neurosci 11:2477-2488.

Warrington AE, Barbarese E, Pfeiffer SE (1993) Differential myelinogenic capacity of specific stages of the oligodendrocyte upon transplantation into hypomyelinating hosts. J Neurosci Res 34:1-13.

Yeh HJ, Ruit KG, Wang YX, Parks WC, Snider WD, Deuel TF (1991) PDGF A-chain gene is expressed by mammalian neurons during development and in maturity. Cell 64:209-216. 